Proceeding Paper

\title{
Seasonal Variation in Wild Ungulate Abundance in a Hunting-Ban Beech Forest: A Case Study of Amiata Mountain, Central Italy ${ }^{+}$
}

\author{
Paolo Viola, Pedro Girotti, Domenico Serafini, Sarah Serafini, Rachele Venanzi, Damiano Tocci and Andrea Amici *
}

Citation: Viola, P.; Girotti, P. Serafini, D.; Serafini, S.; Venanzi, R.; Tocci, D.; Amici, A. Seasonal Variation of Wild Ungulates Abundance in a Hunting-Ban Beech Forest: A Case Study of Amiata Mountain, Central Italy. Environ. Sci. Proc. 2021, 3, 34. https://doi.org/ 10.3390/IECF2020-07879

Academic Editors: Angela Lo Monaco, Cate Macinnis-Ng and Om P. Rajora

Published: 11 November 2020

Publisher's Note: MDPI stays neutral with regard to jurisdictional claims in published maps and institutional affiliations.

Copyright: $₫ 2020$ by the authors. Licensee MDPI, Basel, Switzerland. This article is an open access article distributed under the terms and conditions of the Creative Commons Attribution (CC BY) license (http://creativecommons.org/licenses/by/4.0/)
Department of Agricultural and Forest Science, University of Tuscia, Via S. C. de Lellis snc 01100 Viterbo, Italy; p.viola82@unitus.it (P.V.); pedro.girotti@gmail.com (P.G.); nole1293@gmail.com (D.S.); sarah.serafini@yahoo.it (S.S.); venanzi@unitus.it (R.V.); tocci@unitus.it (D.T.)

* Correspondence: amici@unitus.it; Tel.: +39-(0)761-357443

+ Presented at the 1st International Electronic Conference on Forests - Forests for a Better Future: Sustainability, Innovation, Interdisciplinarity, 15-30 November 2020; Available online: https://iecf2020.sciforum.net.

\begin{abstract}
Several studies have focused on the impact of ungulates on agricultural systems, but the magnitude of their antagonistic role in forest renovation dynamics has long been underestimated and is rarely considered. The abundance of ungulate species is susceptible to seasonal variations according to their autecology, human management choices, and territorial planning. Therefore, the appropriate choice of counting period is crucial. In this case study, we used camera traps to assess the seasonal abundance variations of wild boar and roe deer in a 560-hectares hunting-ban beech forest $(95.48 \%)$ in southern Tuscany managed for timber production. Camera-trapping sessions were performed in both early summer and autumn. The roe deer abundance index is higher in early summer, although statistically not significant, potentially affecting seedling survival. Inversely, wild boars significantly $(F=79.125 ; p=0.001)$ increase their abundance at the local scale in autumn when probably, according to the ecology of fear, they shift their home range toward refuge areas temporary. In autumn, the high density of wild boars can reduce seed availability at the local scale. Further analyses assessing the correlation between seasonal wild ungulate abundance and forest regeneration rates are in progress, based on data recorded within and around three fenced sample plots.
\end{abstract}

Keywords: camera trapping; CPUE; density estimation; relative abundance index; seasonal density variation; REM; roe deer; wild ungulates; wild boar

\section{Introduction}

The impact of wild ungulates on forests started being taken into account in the second half of the twentieth century [1-3], when the exponential growth of their populations started, driven by mountainous area abandonment and consequent secondary forest successions [4-6]. These species can affect forest regeneration, structure, and functioning in different ways according to their feeding behaviour $[7,8]$. The final cumulative effects can be positive, neutral, or negative on the basis of their density, the ecosystem stability, and the forest management strategy used [8,9]. However, the antagonistic role of these species has long been underestimated and is rarely considered [10]. A recent study [8] demonstrated that the effects on forest are more negative as ungulate abundance increases. A rapid neutral to negative shift of effects occurs when the ungulate density reaches a threshold of 15 roe deer, 2.3 red deer, and 4.3 wild boars per $\mathrm{km}^{2}$. Therefore, the counting of each species should be performed when the forest is potentially sensitive to speciesspecific feeding behaviour and when the abundance of the species is the highest at the local scale. 
Here, we present only preliminary results from the first step of an in-progress multiyear project aiming to assess the relation existing between the seasonal wild ungulate abundance and beech (Fagus sylvatica) forest regeneration rate in a hunting ban context.

In this preliminary stage, we used camera traps (CTs) aiming to: (i) assess wild boar (Sus scrofa) and roe deer (Capreolus capreolus) relative abundance; (ii) assess eventual seasonal abundance variations useful to define the best moment for counting each species; (iii) estimate their absolute abundance (density); (iiii) assess the seasonal movement rate and time spent by each species in foraging activity within the field of view of CTs.

\section{Materials and Methods}

\subsection{Study Area}

The study was conducted within a mountain area of 560 hectares on the east face of the Amiata Mountain, which is an isolated volcanic relief located in Siena province (south of Tuscany region, Italy). A monospecific beech (Fagus sylvatica L.) forest $(95.48 \%$ ) principally covers the study area. The area approximately extends from $42^{\circ} 52^{\prime} 35.00^{\prime \prime}$ to $42^{\circ} 54^{\prime} 09.00^{\prime \prime} \mathrm{N}$ and from $11^{\circ} 37^{\prime} 17.00^{\prime \prime}$ to $11^{\circ} 38^{\prime} 27.00^{\prime \prime} \mathrm{E}$.

The altitude ranges between 1116 and $1731 \mathrm{~m}$ a.s.l., typically lying in the Fagetum phytoclimatic band. The forest is subjected to a shelterwood cutting silvicultural system for timber production and is rather homogeneous for both ecological conditions and anthropic management. The area is under a hunting ban due to the regional law 3/1994 that identifies the area as a wildlife protection zone.

\subsection{Data Recording}

A stratified sampling procedure was adopted to choose camera trap (CT) locations (Moeller et al., 2018). A fishnet of $1.5 \times 1.5 \mathrm{~km}$ grids was generated overlapping the study area. The grid, encompassing all the three forest classes covering the study area, was chosen and then divided into nine equal sections. We placed one CT (MultiPIR-12) into each sub-plot randomly, ensuring that the number of CTs in each forest class was proportional to the forest class representativeness. The CTs detection radius $(\mathrm{r})$ and angle $(\theta)$ were determined by a field test [11,12], resulting in $5.41 \mathrm{~m}$ and 1.13 radians. Although standard approaches provide, for wild boar in particular, counting during the summer [13], we planned and performed CT sessions in both summer (June) and autumn (November).

\subsection{Relative Abundance Index and Density Estimation}

The trapping rate (TR) was computed as follows and multiplied by 100 as in Rovero and Marshall [14]:

$$
\mathrm{TR}=\frac{\mathrm{y}}{\mathrm{t}} \times 100,
$$

where $y$ is the total number of independent photographic events and $t$ is the total detection effort computed as follows:

$$
\mathrm{t}=\frac{\text { CTS number } \times \text { haours of work }}{24 \mathrm{~h}} .
$$

The Random Encounter Model (REM) [14,15] rescales linearly the trapping rate (y/t) to the population density considering two main biological variables, the average group size (AGS) and the average daily range (ADR: $\mathrm{km} /$ day), and two CTs parameters, detection radius $(r)$ and angle $(\theta)$. We used the following REM equation [15] to estimate the roe deer and wild boar density (D) starting from TR $(y / t)$ :

$$
\mathrm{D}=\frac{\mathrm{y}}{\mathrm{t}} \times \frac{\pi}{\operatorname{DR} \times \mathrm{r} \times(2+\theta)} .
$$

As expected for a social species, D was corrected for the average group size. ADR and average resting time (ART) were considered as useful indices of two behaviours: feeding or moving between habitats searching for resources. 


\subsection{Statistical Analysis}

We defined 4 seasons-species subsets to assess TR and estimate D: summer roe deer (SRD), autumn roe deer (ARD), summer wild boar (SWB), and autumn wild boar (AWB). For each subset, ADR and ART were also assessed. The average trapping rate (ATR), ADR, and ART and the respective variances were computed separately for each subset, considering three repetitions of equal duration in both summer and autumn. A one-way ANOVA with bootstrapping (1,000 iterations) was used to assess, by species between two seasons, differences in the trapping rate (TR) and other behavioural parameters (MGS, $\mathrm{ADR}$, and ART). The overall variance in the REM density estimation was computed with non-parametric bootstrap re-sampling CT locations with 10,000 replacements, as in Rowcliffe et al. [15].

\section{Results and Discussion}

During the summer session, 64 and 32 independent photographic events were recorded for roe deer and wild boar, respectively, while in autumn there were 20 and 171, respectively.

In Table 1, a summary of the camera trapping effort, records, TR and average trapping rate (ATR) for each one of the four season-species subsets were reported.

Table 1. Camera trapping effort in days $(t)$, total independent events $(y)$ for each species, total trapping rate (TR), and average trapping rate (ATR) for each season-species subset. ATR is reported as mean $\pm \mathrm{SE}$.

\begin{tabular}{ccccc}
\hline Season-Species $^{\mathbf{1}}$ & $\mathbf{t}$ & $\mathbf{y}$ & TR $^{2}$ & ATR \\
\hline SRD & 185 & 64 & 34.59 & $34.51 \pm 5.53$ \\
ARD & 213 & 20 & 9.39 & $9.45 \pm 3.12$ \\
SWB & 185 & 32 & 17.30 & $17.33 \pm 1.52$ \\
AWB & 213 & 171 & 80.28 & $79.07 \pm 4.48$ \\
\hline
\end{tabular}

${ }^{1} \mathrm{SRD}=$ summer roe deer; $\mathrm{ARD}=$ autumn roe deer; $\mathrm{SWB}=$ summer wild boar; $\mathrm{AWB}=$ autumn wild boar. ${ }^{2} \mathrm{TR}=(\mathrm{y} / \mathrm{t}) \times 100$.

The roe deer and wild boar abundance (Table 1) showed an inverse trend, with the roe deer TR higher in summer than in autumn, and the WB abundance index higher in autumn than in summer. The average group size (AGS) and average daily range (ADR), which are the independent variables required to estimate REM density starting from TR, are reported in Table 2 for each season-species subset. In the same table, ART and REM density estimates are also reported.

Table 2. Average group size (AGS), average daily range (ADR), average resting time (ART), and density estimates (REM) for each season-species subset. Estimates are reported as mean $\pm \mathrm{SE}$, except REM density, for which the $95 \%$ confidence interval (C.I.) is provided.

\begin{tabular}{cccccc}
\hline Sub-Sets & \multicolumn{3}{c}{ Variable for REM Estimation } & \multicolumn{2}{c}{ REM } \\
\hline Season-Species ${ }^{1}$ & AGS (n $\left.{ }^{\circ}\right)$ & ADR (km/day) & ART (s) & \multicolumn{2}{c}{ D (Animals/km ( $\left.^{2}\right)$} \\
\hline SRD & $1 \pm 0.00$ & $15.66 \pm 1.03$ & $52.79 \pm 9.25$ & 10.405 & $(4.482-17.348)$ \\
ARD & $1.27 \pm 0.09$ & $19.79 \pm 4.32$ & $18.14 \pm 3.72$ & 1.264 & $(0.206-2.601)$ \\
SWB & $2.35 \pm 0.11$ & $18.75 \pm 0.77$ & $21.38 \pm 0.69$ & 5.825 & $(1.943-10.792)$ \\
AWB & $2.66 \pm 0.14$ & $37.13 \pm 4.00$ & $41.22 \pm 2.99$ & 9.931 & $(5.595-14.239)$ \\
\hline
\end{tabular}

${ }_{1}^{1} \mathrm{SRD}=$ summer roe deer; $\mathrm{ARD}=$ autumn roe deer; $\mathrm{SWB}=$ summer wild boar; $\mathrm{AWB}=$ autumn wild boar.

Neither of the species showed evident changes in their group dimensions (AGS) and compositions. During the summer, roe deer were solitary according to the territorial (males) and parental (females) phase of the species' biological cycle. Additionally, in autumn roe deer were principally alone, except for two cases when they resulted in a group 
of three individuals composed of a mother with a newborn and the female of the previous year. In contrast, wild boars moved in groups during both seasons according to the afterbirths phase of the biological cycle and the typical social structure of the species. Only in $18 \%$ of the total cases were lone males photographed.

The results of the variance analysis are reported in Table 3, which also reports the statistical significance of the above-observed differences between ATR, AGS, ADR, and ART.

Table 3. Season effect ( $F$-test at $p=0.05$ ) on average trapping rate (ATR), average group size (AGS), average daily range (ADR), and average resting time (ART). Significant differences are shown in bold.

\begin{tabular}{ccccccccccc}
\hline \multicolumn{2}{c}{ Dependent Variable } & \multicolumn{2}{c}{ ATR } & \multicolumn{2}{c}{ AGS } & \multicolumn{2}{c}{ ADR } & \multicolumn{2}{c}{ ART } \\
\hline Species & Effects & $\boldsymbol{F}$ & $\boldsymbol{p}$ & $\boldsymbol{F}$ & $\boldsymbol{p}$ & $\boldsymbol{F}$ & $\boldsymbol{p}$ & $\boldsymbol{F}$ & $\boldsymbol{p}$ \\
\hline $\mathrm{RD}^{1}$ & Season & 6.844 & 0.059 & 3.419 & 0.138 & 0.395 & 0.564 & 4.566 & 0.099 \\
\hline $\mathrm{WB}^{2}$ & Season & 79.125 & $\mathbf{0 . 0 0 1}$ & 1.409 & 0.301 & 9.467 & $\mathbf{0 . 0 3 7}$ & 19.638 & $\mathbf{0 . 0 1 1}$ \\
\hline
\end{tabular}

${ }^{1}$ Roe deer and ${ }^{2}$ wild boar.

The variance analysis (Table 3 ) did not confirm the expected seasonal variation in roe deer abundance (Table 1$)$. In contrast, a highly significant seasonal $(p \leq 0.01)$ effect on wild boar ATR and ART was confirmed by ANOVA. A less significant seasonal effect $(p<0.05)$ was also recorded on the wild boar ADR. The food exploitation hypothesis [16,17], climate-limiting factors [18], and hunting disturbance [19-22] are all possible drivers of wild ungulates' home range shifting and temporal abundance variation at the local scale. According to the ecology of fear [23], animals try to avoid predation risk, shifting their home range toward refuge areas and temporarily limiting their movements outside the sphere of influence of the refuge [24]. On the contrary, when the fear pulse stops, normally at the end of the hunting season (end of January), resources within the refuge decrease and adverse climatic conditions start, and wild boars progressively shift their distribution to plain and hills areas, searching for food with a higher energetic value with a lower search effort [25]. In this case, the study area is a forest with a hunting ban and the autumn (November) corresponds to both the fruit fall period and the beginning of hunting. Therefore, we considered it plausible that the significant increase in the wild boar abundance index recorded during the autumn session may be dependent on the combined effect of both resource availability and hunting disturbance. Given these results, we propose, for future studies, to take into serious account wild boar concentrations, because they could determine a significant reduction in seed availability for forest regeneration, wild boar concentrations should be seriously considered because they could determine a significant reduction in seeds available for forest regeneration [26]. Above-ground plant material represents a higher food supply percentage for wild boars, and fruits and seeds are the most represented $[27,28]$. According to this evidence, we recorded a significantly longer time spent by wild boars in feeding within the field of view of the cameras during autumn, corresponding with the Fagacee seeds fall periods, than in summer, when wild boars were only observed moving between habitats.

\section{Conclusions}

In conclusion, aiming to investigate and define the relative (TR) or absolute (density) abundance threshold beyond which wild ungulates have a negative effect on mountain beech forest regeneration in an area with a hunting ban, our preliminary results suggest significantly higher TR and D for wild boars in autumn compared to early summer, and an inverse trend for roe deer, although without significant differences. For the above reasons, wild boar counts should be performed in autumn, when their significant increase in abundance, at the local scale, can reduce the amount of seeds available for forest regeneration. In contrast, the abundance of roe deer in mountain beech forest with a hunting ban 
should be investigated in the late spring-early summer, when it seems plausible that there is an effect on seedling survival because of the selective browsing attitude of this species.

Author Contributions: The individual contributions provided by the authors were as follows: conceptualization, A.A. and P.V.; methodology, A.A. and P.V.; software, P.V., D.S., and P.G.; validation, A.A, and R.V.; formal analysis, P.V., S.S., and A.A.; investigation, P.G., R.V., and D.T.; resources, A.A.; data curation, P.G., D.S., D.T., and R.V.; writing-original draft preparation, P.V., A.A., and R.V.; writing - review and editing, P.V., A.A., D.T., and S.S.; visualization, A.A., R.V., and P.V.; supervision, A.A.; project administration, A.A.; funding acquisition, A.A. All authors have read and agreed to the published version of the manuscript.

Funding: This research was funded by Macchia Faggeta Forest Society.

Acknowledgments: We acknowledge the administrative and technical help of Macchia Faggeta Forest Society for the logistic support given.

Conflicts of Interest: The authors declare no conflict of interest. The funders had no role in the design of the study; in the collection, analysis, or interpretation of data; in the writing of the manuscript; or in the decision to publish the results.

\section{References}

1. Gill, R.M.A. A review of damage by mammals in north temperate forests: 3. Impact on trees and forests. Forestry 1992, 65, 363388, doi:10.1093/forestry/65.4.363-a.

2. Ammer, C. Impact of ungulates on structure and dynamics of natural regeneration of mixed mountain forests in the Bavarian Alps. For. Ecol. Manag. 1996, 88, 43-53, doi:10.1016/S0378-1127(96)03808-X.

3. Reimoser, F.; Gossow, H. Impact of ungulates on forest vegetation and its dependence on the silvicultural system. For. Ecol. Manag. 1996, 88, 107-119.

4. Massei, G.; Genov, P.V. The environmental impact of wild boar. Galemys 2004, 16, 135-145.

5. Cutini, A.; Chianucci, F.; Apollonio, M. Wild ungulates and forests in Europe: insights from long term studies in Central Italy. In Proceedings of the Atti del Secondo Congresso Internazionale di Selvicoltura = Proceedings of the Second International Congress of Silviculture; Accademia Italiana di Scienze Forestali: Firenze, Italiy, 2015; pp. 509-517.

6. Höchtl, F.; Lehringer, S.; Konold, W. "Wilderness": What it means when it becomes a reality-A case study from the southwestern Alps. Landsc. Urban Plan. 2005, 70, 85-95, doi:10.1016/j.landurbplan.2003.10.006.

7. Bongi, P.; Tomaselli, M.; Petraglia, A.; Tintori, D.; Carbognani, M. Wild boar impact on forest regeneration in the northern Apennines (Italy). For. Ecol. Manag. 2017, 391, 230-238, doi:10.1016/j.foreco.2017.02.028.

8. Ramirez, J.I.; Jansen, P.A.; Poorter, L. Effects of wild ungulates on the regeneration, structure and functioning of temperate forests: A semi-quantitative review. For. Ecol. Manag. 2018, 424, 406-419.

9. Pellerin, M.; Saï, S.; Richard, E.; Hamann, J.L.; Dubois-Coli, C.; Hum, P. Impact of deer on temperate forest vegetation and woody debris as protection of forest regeneration against browsing. For. Ecol. Manag. 2010, 260, 429-437, doi:10.1016/j.foreco.2010.04.031.

10. Vacek, Z.; Vacek, S.; Bílek, L.; Král, J.; Remeš, J.; Bulušek, D.; Králícek, I. Ungulate impact on natural regeneration in sprucebeech-fir stands in Černý důl nature reserve in the Orlické hory Mountains, case study from central sudetes. Forests 2014, 5, 2929-2946, doi:10.3390/f5112929.

11. Nakashima, Y.; Fukasawa, K.; Samejima, H. Estimating animal density without individual recognition using information derivable exclusively from camera traps. J. Appl. Ecol. 2018, 55, 735-744, doi:10.1111/1365-2664.13059.

12. Cusack, J.J.; Swanson, A.; Coulson, T.; Packer, C.; Carbone, C.; Dickman, A.J.; Kosmala, M.; Lintott, C.; Rowcliffe, J.M. Applying a random encounter model to estimate lion density from camera traps in Serengeti National Park, Tanzania. J. Wildl. Manag. 2015, 79, 1014-1021, doi:10.1002/jwmg.902.

13. Keuling, O.; Sange, M.; Acevedo, P.; Podgorski, T.; Smith, G.; Scandura, M.; Apollonio, M.; Ferroglio, E.; Vicente, J. Guidance on estimation of wild boar population abundance and density: methods, challenges, possibilities. EFSA Support. Publ. 2018, 15, doi:10.2903/sp.efsa.2018.en-1449.

14. Rovero, F.; Marshall, A.R. Camera trapping photographic rate as an index of density in forest ungulates. J. Appl. Ecol. 2009, 46, 1011-1017, doi:10.1111/j.1365-2664.2009.01705.x.

15. Rowcliffe, J.M.; Field, J.; Turvey, S.T.; Carbone, C. Estimating animal density using camera traps without the need for individual recognition. J. Appl. Ecol. 2008, 45, 1228-1236, doi:10.1111/j.1365-2664.2008.01473.x.

16. Bisi, F.; Chirichella, R.; Chianucci, F.; Von Hardenberg, J.; Cutini, A.; Martinoli, A.; Apollonio, M. Climate, tree masting and spatial behaviour in wild boar (Sus scrofa L.): Insight from a long-term study. Ann. For. Sci. 2018, 75, doi:10.1007/s13595-0180726-6.

17. Larter, N.C.; Gates, C.C. Home-Range Size of Wood Bison: Effects of Age, Sex, and Forage Availability. J. Mammal. 1994, 75, 142-149. 
18. Cagnacci, F.; Focardi, S.; Heurich, M.; Stache, A.; Hewison, A.J.M.; Morellet, N.; Kjellander, P.; Linnell, J.D.C.; Mysterud, A.; Neteler, M.; et al. Partial migration in roe deer: Migratory and resident tactics are end points of a behavioural gradient determined by ecological factors. Oikos 2011, 120, 1790-1802, doi:10.1111/j.1600-0706.2011.19441.x.

19. Keuling, O.; Stier, N.; Roth, M. How does hunting influence activity and spatial usage in wild boar Sus scrofa L.? Eur. J. Wildl. Res. 2008, 54, 729-737, doi:10.1007/s10344-008-0204-9.

20. Grignolio, S.; Merli, E.; Bongi, P.; Ciuti, S.; Apollonio, M. Effects of hunting with hounds on a non-target species living on the edge of a protected area. Biol. Conserv. 2011, 144, 641-649, doi:10.1016/j.biocon.2010.10.022.

21. Thurfjell, H.; Spong, G.; Ericsson, G. Effects of hunting on wild boar Sus scrofa behaviour. Wildlife Biol. 2013, 19, 87-93, doi:10.2981/12-027.

22. Vajas, P.; Calenge, C.; Richard, E.; Fattebert, J.; Rousset, C.; Saïd, S.; Baubet, E. Many, large and early: Hunting pressure on wild boar relates to simple metrics of hunting effort. Sci. Total Environ. 2020, 698, doi:10.1016/j.scitotenv.2019.134251.

23. Brown, J.S.; Laundré, J.W.; Gurung, M. The ecology of fear: Optimal foraging, game theory, and trophic interactions. J. Mammal. 1999, 80, 385-399, doi:10.2307/1383287.

24. Tolon, V.; Dray, S.; Loison, A.; Zeileis, A.; Fischer, C.; Baubet, E. Responding to spatial and temporal variations in predation risk: Space use of a game species in a changing landscape of fear. Can. J. Zool. 2009, 87, 1129-1137, doi:10.1139/Z09-101.

25. Held, S.; Baumgartner, J.; Kilbride, A.; Byrne, R.W.; Mendl, M. Foraging behaviour in domestic pigs (Sus scrofa): Remembering and prioritizing food sites of different value. Anim. Cogn. 2005, 8, 114-121, doi:10.1007/s10071-004-0242-y.

26. Wirthner, S. The Role of Wild Boar (Sus scrofa L.) Rooting in Forest Ecosystems in Switzerland. Ph.D. Thesis, University of Bern, Bern, Switzerland, 2011.

27. Herrero, J.; Irizar, I.; Laskurain, N.A.; García-Serrano, A.; García-González, R. Fruits and roots: Wild boar foods during the cold season in the southwestern pyrenees. Ital. J. Zool. 2005, 72, 49-52, doi:10.1080/11250000509356652.

28. Rodríguez-Estévez, V.; Sánchez-Rodríguez, M.; Gómez-Castro, A.G.; Edwards, S.A. Group sizes and resting locations of free range pigs when grazing in a natural environment. Appl. Anim. Behav. Sci. 2010, 127, 28-36, doi:10.1016/j.applanim.2010.08.010. 